\title{
ELECTROQUIMIENERGÍA Y CAMBIO CLIMÁTICO: UNA REVISIÓN
}

\author{
ELECTROCHEMENERGY AND CLIMATE CHANGE: A REVIEW
}

\author{
Jairo Márquez P1 ., Olga P. Márquez ${ }^{1 *}$, Yris Martínez',

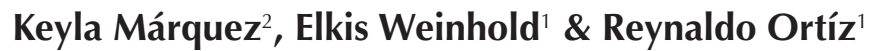

Recibido: 9 de noviembre 2021 / Aceptado: 14 de enero 2022

DOI 10.26807/ia.v10i1.229

Palabras clave: baterías, cambio climático, celdas solares, electroquimienergía, energías renovables, energía solar Keywords: batteries, climate change, electrochemenergy, renewable energies, solar cells, solar energy.

\section{RESUMEN}

La situación actual que se vive requiere de una adicional y urgente atención por parte de las Ciencias, Ingenierías y Tecnologías para control ambiental, climático, sanitario, por el bienestar y para la vida en el planeta. El área científica que concierne a este trabajo, la electroquimienergía (EQ.E), involucra importantes contribuciones sobre esta temática y son muchas y variadas las

1 Universidad de Los Andes, Laboratorio de Electroquímica, Departamento de Química, Facultad de Ciencias. Mérida, Venezuela (jokkmarquez82@gmail.com, * correspondencia: olgamq@gmail.com, ymartin62@gmail.com, elkisweinhold@gmail.com, reynaldoluis@gmail.com)

2 Universidad de Los Andes, Núcleo Alberto Adriani, Facultad de Ingeniería. El Vigía, Venezuela (keylaenator@gmail.com) 
nuevas contribuciones por realizar. En esta revisión se presentan algunos de esos estudios, unos terminados, algunos en marcha y otros por realizar; es de resaltar la importancia actual de trabajo conjunto con los campos de la nanociencia y la nanocatálisis, en el área científica.

\section{ABSTRACT}

The current situation requires additional and urgent attention from Science, Engineering and Technology regarding environmental, climatic, and sanitary control, for the well-being and life over the planet. The scientific area that concerns this work, Electrochemenergy (EC.E), involves important contributions on this subject and there are many and varied new contributions to be made. This review presents some of these studies, some of them completed, others in progress and others to be carried out; it is important to highlight the current importance of working together with the fields of nanoscience and nanocatalysis in the scientific area.

\section{INTRODUCCIÓN}

El cambio climático $(\mathbf{C C l})$ actual, inducido y con características tales como la contaminación ambiental (aire, suelos y aguas, y de los sistemas ecológicos); la promoción y aumento en la frecuencia y gravedad de los desastres naturales; el calentamiento global y las glaciaciones, entre otros fenómenos que ocurren, son atribuidos en buena medida al uso de combustibles fósiles como fuente energética y a la contamina- ción industrial. Por otra parte, se cuenta con fuentes energéticas inagotables, disponibles y accesibles, que son actualmente de imprescindible y conveniente atención (energías renovables).

Las energías renovables se obtienen a partir de fuentes naturales inagotables y generan electricidad sin contribuir al calentamiento global. La humanidad busca actualmente un 
sistema energético fiable, asequible y no contaminante. Las energías renovables se diferencian de los combustibles fósiles principalmente por su diversidad, abundancia, accesibilidad y potencial aprovechamiento en todo el planeta (Baxter et al., 2009); son de muy poca o de nula contaminación, sin contribución al efecto invernadero y contaminación ambiental.

El desarrollo de energías limpias es imprescindible para la implementación del acceso mundial a la electricidad y paralelamente controlar el cambio climático, la contaminación ambiental, contribuyendo así al saneamiento del planeta (Márquez \& Márquez, 2018).

Son energías renovables: (a) Eólica (se obtiene de los vientos); (b) Solar: Fotovoltaica (aprovecha la luz del Sol) y Térmica (aprovecha el calor solar); (c) Hidráulica o hidroeléctrica (se obtiene de ríos y corrientes de agua dulce); (d) Geotérmica (contenida en el interior de la tierra); (e) Mareomotriz (se obtiene de las mareas); (f) Undimotriz u olamotriz (se obtiene de las olas marinas); (g) Biomasa y biogás (se extrae de la materia orgánica); (h) Bioetanol (combustible orgánico, etanol, obtenido en procesos de fermentación de productos vegetales); (i) Biodiesel (combustible orgánico que se obtiene a partir de aceites vegetales).

El sector energético (Guía de la energía solar, España, 2006) es la fuente más importante de emisión de gases de efecto invernadero $y$, en consecuencia, del cambio climático. Los principales gases producidos son: el $\mathrm{CO}_{2}$ y el $\mathrm{CH}_{4}$, derivados de la quema de combustibles fósiles (transporte, industria, etc.), así como el de las minas de carbón, y de las instalaciones de hidrocarburos y gas. Los sectores transformadores "producción de electricidad" y "refino" tienen un aporte al efecto invernadero del 30 $\%$. Los requerimientos actuales a nivel mundial, en los campos energético, económico, salud, comunicación, seguridad, ambiente, servicios y bienestar comunitario, urgen por el acceso sin limitaciones al recurso energético (Márquez, Márquez, Weinhold, Márquez, 2021; Wulfinghoff, 1999)

En la práctica, ello se traduce en la disposición general sin restricciones, 
en primera instancia, del recurso energético desde fuentes seguras, disponibles, ilimitadas, accesibles, variadas, no contaminantes y económicas. De las fuentes disponibles, el hidrógeno (fuente secundaria de energía) cumple con buena parte de estas exigencias y ello explica la creciente actividad científico-técnica, los nuevos desarrollos y nuevas aplicaciones de este recurso.

La Humanidad ha utilizado, a lo largo de su historia, los diferentes recursos energéticos existentes en la naturaleza; Inicialmente, energía pre1sente en la biomasa, vientos, corrientes de agua y solar. El origen común de estas energías se sabe que es proveniente del Sol, mediante el proceso fisicoquímico de fusión nuclear. Posteriormente comienza la explotación de combustibles fósiles, carbón, petróleo y gas, acumuladores también de energía Solar. Luego, son descubiertas y comienza el uso, de energías nuclear, geotérmica y mareomotriz.

Estas fuentes energéticas de uso directo son denominadas fuentes energéticas primarias, y se clasifican según su finitud, en energías no re- novables (fósiles y nuclear) y renovables, el resto de las energías (solar, eólica, hidráulica, biomasa, marina, geotérmica, entre otras). El hidrógeno es un vector de almacenamiento energético, con novedosas aplicaciones en transporte y celdas de combustible, y su obtención, mediante procesos del tipo electrólisis, fotoelectrólisis o fotoelectroquímico, se suman a esa actual exigencia de nula contaminación, simplicidad y economía en la síntesis.

\section{Energía, ambiente, servicios, usos y clima}

Impactos ambientales asociados con la energía (Moreno, et al., 2017; Márquez \& Márquez, 2018) se deben a su obtención, el transporte y su uso. La quema de carbón, gas natural y petróleo para la electricidad y el calor es la principal fuente de emisiones globales de gases de efecto invernadero. También hay quema de combustibles fósiles en las instalaciones de energía en el sector industrial. Hay emisiones de gases de efecto invernadero en el sector agrícola, pecuario, silvicultura y deforestación. En el sector transporte hay emisiones de gases de efecto invernadero por quema de 
combustibles fósiles para el transporte por carretera, ferrocarril, aire y mar. Las emisiones de gases de efecto invernadero en el sector doméstico surgen de la generación de energía in situ y la quema de combustibles para calefacción y procesos de cocinado en hogares y hay emisiones también en la extracción, refinado, procesamiento y transporte de combustible.

La quema de combustibles para generar electricidad en centrales térmicas, para la calefacción en hogares, para cocinar, para el transporte, genera cenizas y humos, y allí se generan emisiones de dióxido de carbono $\left(\mathrm{CO}_{2}\right)$, óxidos de azufre $\left(\mathrm{SO}_{\mathrm{x}}\right)$ y óxidos de nitrógeno $\left(\mathrm{NO}_{\mathrm{x}}\right)$. El $\mathrm{CO}_{2}$ es un gas de efecto invernadero y los compuestos de azufre y nitrógeno, son responsables de la Iluvia ácida, su combinación con oxígeno y agua forman los ácidos, nítrico $\mathrm{HNO}_{3}$ y sulfúrico $\mathrm{H}_{2} \mathrm{SO}_{4}$, con impacto negativo en el hábitat de la zona.

Los servicios energéticos más relevantes por sectores de consumo son: (a) industria; (b) Transporte; (c) residencial; (d) comercial: (e) Público; (f) agropecuario y $(d)$ servicios.
También se presentan fenómenos de origen natural, que pueden convertirse en problemas ambientales: (a) inundaciones; (b) sismos; (c) deslizamiento de tierras; (d) vulcanismo. Otros problemas de origen antrópicos debido al manejo inadecuado de recursos naturales son: (a) deforestación; (b) desertificación; (c) inundaciones; (d) contaminación hídrica, superficial o subterránea; (e) contaminación del aire; (f) recarga insuficiente de acuíferos; (g) impermeabilización de suelos; (h) contaminación en general (residuos radioactivos y otros contaminantes); (i) otros. Globalmente, la sumatoria de problemas ambientales está ocasionando enormes cambios en el ecosistema, como lo son, emanaciones de gases de efecto invernadero, cambio climático, extinción de especies, reducción de la biodiversidad, pérdida de hábitat, entre otros.

\section{Contribuciones de la electroquimie- nergía (EQ.E)}

La EQ.E se encuentra en las ciencias naturales, ciencias de la salud, ingenierías, educación, actividad militar, y en la tecnología. Con un poco más de detalle, se enfocará en lo social, 
hogar, ambiente, salud, energía, beIleza, alimentación, medicamentos, enfermedad, electrónica, defensa e industria; se pueden mencionar actividades específicas como ambiente y contaminación (descontaminación ambiental, purificación de aguas, tratamiento de suelos); cuerpo humano (enfermedad, medicamentos, tratamientos, productos de belleza y mantenimiento, electroterapia, afecciones orgánicas, iontoforesis, electroshock, marcapasos, depilación, cremas, lociones, aplicaciones); energía, captura, almacenamiento, conversión, suministro y sus aplicaciones (celdas fotovoltaicas, pilas y baterías, almacenamiento en químicos, celdas de combustible); vivienda y vida social, alumbrado, electrodomésticos, cocción de alimentos, calefacción, refrigeración, tratamiento de aguas, transporte; electrónica, sensores, detectores, armamento y numerosos tópicos industriales. El cambio climático en proceso obliga a tomar medidas urgentes que puedan contribuir favorablemente a una sana estabilización climática y en ese sentido, en el área tecno-científica, se plantea una actividad más abundante y avanzada en investigación, desarrollos, diseños, modificaciones, construcción, escalados, mejoras, etc. En la Tabla 1, se señalan algunos tópicos de requerida atención, dentro de la problemática señalada.

\section{Tabla 1. Contribución electroquímica al restablecimiento de condiciones climáticas sanas y al ambiente}

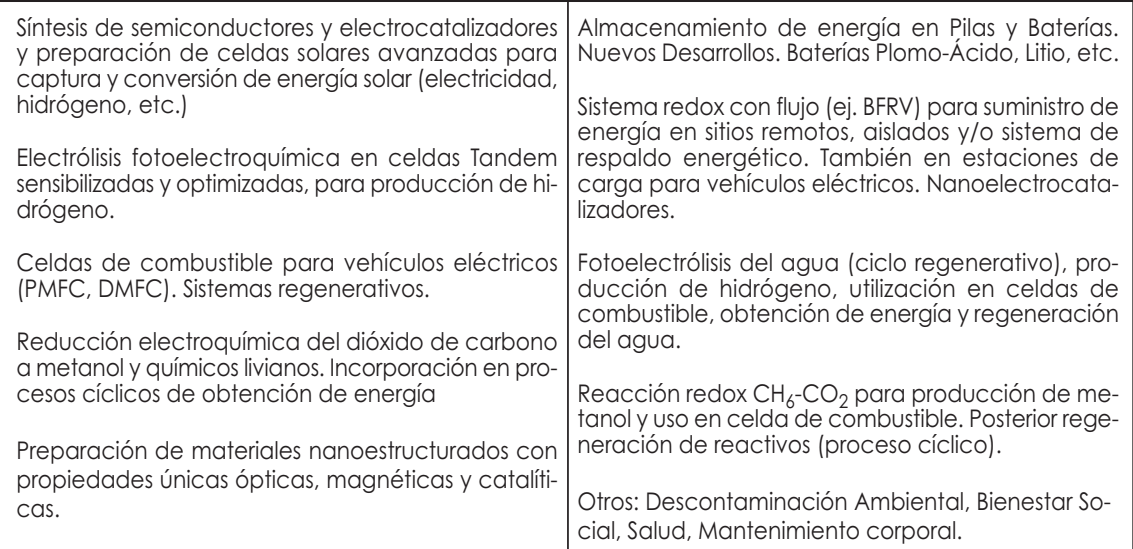




\section{Proceso fotovoltaico: síntesis electro- química de semiconductores}

Mediante la utilización de técnicas electroquímicas, es posible controlar diversas propiedades semiconductoras tales como: conductividad, estequiometría, variación en la brecha energética, tipo de dopaje, etc., así como también, parámetros tales como, potenciales, densidades de corriente, tiempo de deposición, entre otros. Se han utilizado métodos electroquímicos en la preparación de semiconductores elementales ( $\mathrm{Si}, \mathrm{Ge}$, $\mathrm{Se}, \mathrm{Te}$, etc.), secundarios (AsGa, CdS, CdSe, CdTe, InSe, $\mathrm{BiS}_{3}$, etc.), compuestos intermetálicos (InSb, CuTe, $\mathrm{PbTe}, \mathrm{HgTe}, \mathrm{NiTe}_{2}$, Etc.), semiconductores ternarios $\left(\mathrm{CuInS}_{2}, \mathrm{CulnSe}_{2}\right.$, CulnTe ${ }_{2}$, AglnSe $_{2}, \mathrm{HgCdTe}$, Etc.) (Lokhande, C. D., 1991), semiconductores cuaternarios y catalizadores electroquímicos para mejoras en eficiencia (Márquez \& Márquez, 2018; Lincot et al., 2004)

La técnica de electrodeposición es muy utilizada en preparación de semiconductores pues ofrece atractivas ventajas, así, por ejemplo, al ser un proceso isotérmico y controlando parámetros eléctricos, se controla el grosor de la película, su morfología, composición, etc. El uso de bajas temperaturas de operación ofrece ventajas, en términos de la energía requerida y permitiendo la disminución de defectos por interdifusión, contaminantes, y redistribución de dopantes. En la fabricación de heterouniones, simplemente cambiando la concentración en las sales precursoras, una película tipo n puede ser depositada sobre un sustrato tipo $\mathrm{p}$.

En la electrodeposición, la utilización de técnicas galvanostáticas, como uno de los pasos en la preparación de semiconductores compuestos, ofrece la posibilidad de preparar estas películas a mayor escala en procesos industriales y también, ofreciendo la posibilidad de combinar esta técnica con otras (ej. deposición química) para desarrollar materiales de mejor calidad.

La electrodeposición se inicia disolviendo las sales precursoras (preferiblemente en forma iónica) de todos los elementos; luego la electrodeposición puede proceder vía catódica o anódica. Entonces la reacción puede ocurrir cuando el potencial aplicado es más bajo en procesos anódicos o 
más alto en procesos catódicos, que el potencial redox de la reacción (Lincot, (2005). Las condiciones experimentales bajo las cuales se Ilevan a cabo los procesos de electrodeposición (densidad de corriente, potencial, concentración y composición del electrolito, acomplejamiento de los iones electroactivos) tienen efectos importantes sobre la morfología y propiedades de los depósitos metálicos obtenidos (Le Penven, Levason, Pletcher, 1992; Gregory, Levason, Pletcher, 1993; Basirun, Pletcher, Saraby-Reintejes, 1996).

Las Calcopiritas I-III-VI han mostrado tener gran potencial fotovoltaico. Eficiencias de conversión hasta de $18 \%$ ha sido alcanzada en celdas solares (como dispositivo fotovoltaico) basadas en películas delgadas de $\mathrm{Cu}(\mathrm{In}, \mathrm{Ga}) \mathrm{Se}_{2}$ con una brecha energética aproximadamente de 1,12 eV (Rusu et al., 2004).

Entre los compuestos semiconductores ternarios más estudiados se encuentran el CulnSe 2 , CulnS 2 y AgInS 2 . Muchos estudios tratan la preparación directa de películas $\mathrm{Cu}$ (In, Ga) $\mathrm{Se}_{2}$ y muestran que la introducción de galio en las películas es posible desde baños sencillos que contengan todos los elementos.

El tratamiento térmico es de una dramática importancia para una apropiada calidad electrónica de las capas; ello es, generalmente, hecho en presencia de un calcogenuro (Se, S) bajo presión, y un rápido proceso térmico. Películas ternarias de calcogenuros se han preparado por: (a) electrocodeposición simultánea de todos los elementos constituyentes; (b) electrodeposición secuencial de los elementos constituyentes; (c) deposición de una aleación seguida por la calcogenización (Lincon et al., 2004: Hodes \& Cahen, 1986; Manfredy et al., 2014; Balladores et al., 2014)

Han aparecido nuevas celdas con altos rendimientos de conversión. A diferencia de las actuales que utilizan silicio como estandar y alcanzan un $33 \%$ de conversión (teórico para celda fotoeléctrica basada en una unión p-n)), estas nuevas celdas, multiunión (seis uniones), añaden nuevos materiales (grupo III-V) absorbentes de luz y distintas capas delgadas fotoactivas (140 capas), especialmente diseñadas para aumentar la eficiencia 
de conversión hasta un 47,1 \%. Cada capa tiene distintos nanomateriales para recoger diferentes partes del espectro solar utilizando luz concentrada (143 soles). La eficiencia de conversión es, sin embargo, de 39,2 $\%$ (sigue siendo record en eficiencia), con luz concentrada de un solo sol. El limite sitúa la eficiencia máxima alrededor del 33,7\%, considerando una única unión p-n con una banda prohibida de 1,34 eV, es decir, de la energía solar incidente $\left(1000 \mathrm{~W} / \mathrm{m}^{2}\right)$, solo el 33,7 \% se podría convertir en electricidad $\left(337 \mathrm{~W} / \mathrm{m}^{2}\right)$ (Geisz et al.,
Procesos electrolítico, fotoelectrolítico, fotolitico y fotoelectroquímico. Celdas (electrolítica, fotoelectrolítica, fotolitica, Tándem-Sensibilizada

El esquema de conversión cíclica del $\mathrm{H}_{2} \mathrm{O}$ (Figura 1) muestra las posibilidades de uso de celda solar, celda fotoelectrolítica, celda electrolítica, celda fotoelectroquímica, batería de almacenamiento de energía, celda de combustible, regeneración del $\mathrm{H}_{2} \mathrm{O}$ y suministro de energía.

2020)

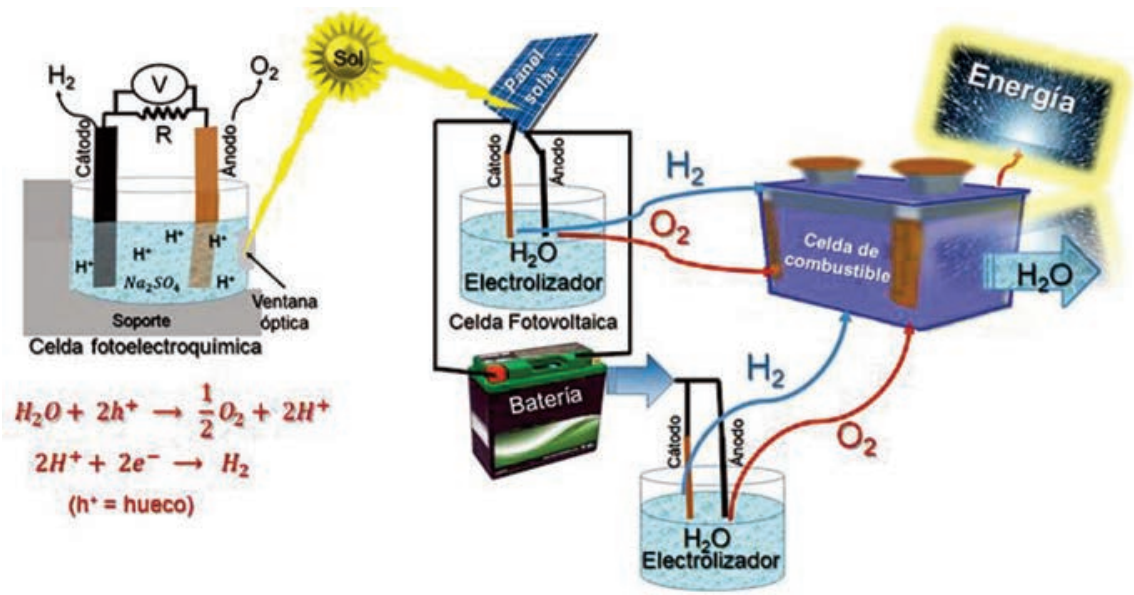

Figura 1. Conversión Cíclica del $\mathrm{H}_{2} \mathrm{O}$ y Suministro de Energía 
La experimentación confirma, una mayor eficiencia Solar a Hidrógeno, en la celda fotoelectrolítica relativo a la celda electrolítica (Fujishima \& Honda, 1972). Para un sistema con una base $12 \%$ de eficiencia fotovoltaica (PV) y eficiencia en la electrólisis del $65 \%(1,9 \mathrm{~V})$, la eficiencia solar a Hidrógeno es del 7,8 \%. $(1,2 \times 6,5=7,8 \mathrm{Ef})$

Para un Sistema de conversión directa (fotoelectroquímica) con base $12 \%$ de eficiencia PV, operando a $1,45 \mathrm{~V}(85 \%)$, la eficiencia Solar a Hidrógeno es de 10,2 \%. (1,2 x X= 10,2 \%) (Figura 2).
En la celda Tándem mostrada en la Figura 3, (Graetzel, 2006). el electrodo tope de trabajo consiste de una película delgada del óxido semiconductor $\mathrm{Fe}_{2} \mathrm{O}_{3}$, el cual absorbe fotones en las regiones verde, azul y ultravioleta de la luz solar que recibe y transmite luz amarilla, roja e infrarrojo. La fotoexcitación produce electrones en la banda de conducción y huecos en la banda de valencia (ec. 1).

$$
\mathrm{Fe}_{2} \mathrm{O}_{3}+h v \rightarrow \mathrm{Fe}_{2} \mathrm{O}_{3}\left(e^{-}-h^{+}\right)
$$

donde $h^{+}=$hueco

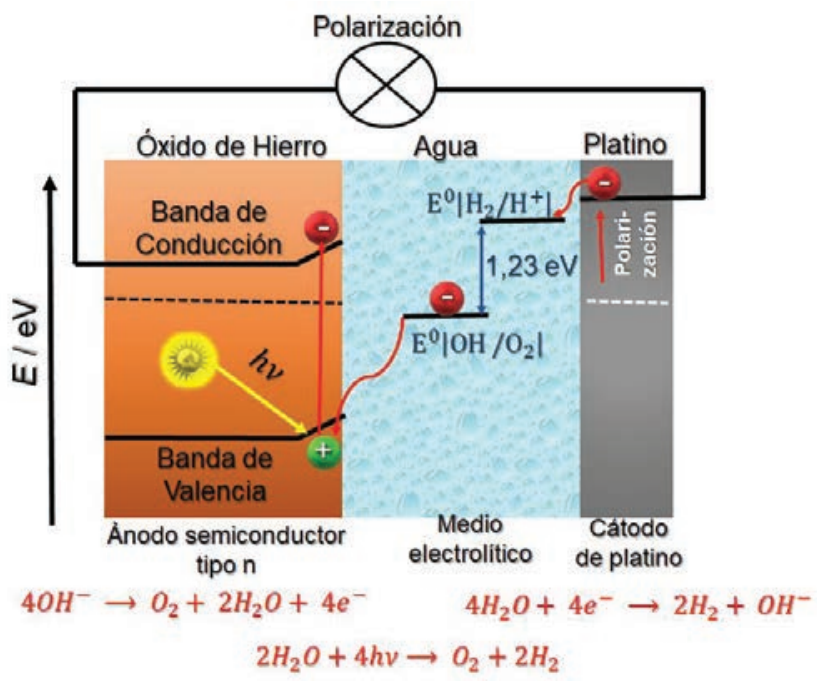

Figura 2. Generación de hidrógeno por Fotoelectrólisis del agua

(Fujishima \& Honda, 1972) 
Colorante de Ru sobre una capa de

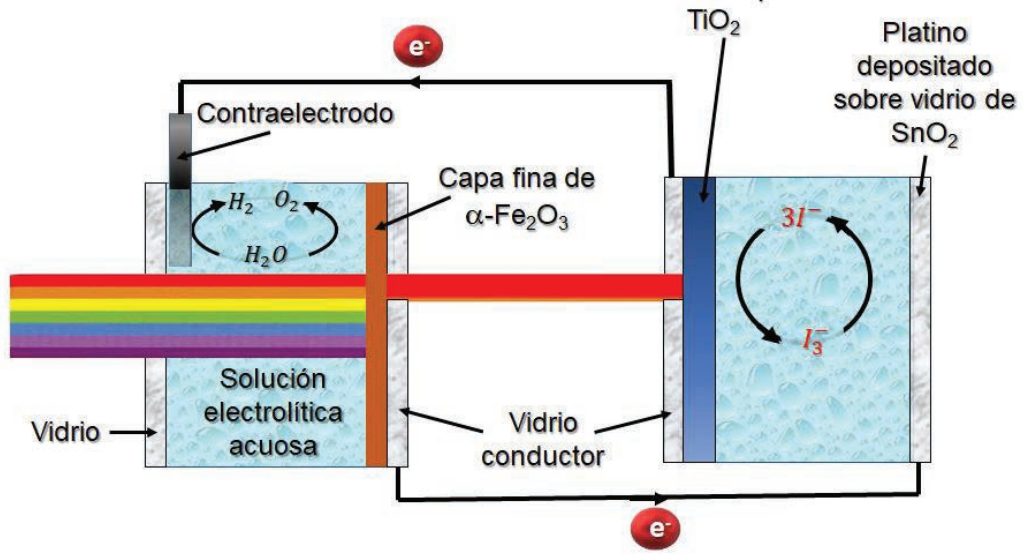

Figura 3. Celda Tándem sensibilizada

(Graetzel, 2006)

Los huecos en la banda de valencia oxidan el agua a oxígeno (ec. 2)

$$
2 h^{+}+2 \mathrm{H}_{2} \mathrm{O} \rightarrow \mathrm{O}_{2}+4 \mathrm{H}^{+}
$$

El potencial químico de los electrones en la banda de conducción es elevado por la celda posterior, proveyendo una ruta eléctrica para la generación de hidrógeno del agua (ec. 3)

$$
4 H^{+}+4 e^{-} \rightarrow H_{2}
$$

\section{Celdas solares en tándem conecta-} das en serie

La adición de más dispositivos permite que cada dispositivo sea opti- mizado para un espectro más estrecho dando una eficiencia global mayor. Las celdas solares en tándem pueden ser o bien celdas individuales o estar conectadas en serie. Las celdas conectadas en serie son más fáciles de fabricar, pero la corriente es la misma a través de cada celda por lo que esto restringe los intervalos de bandas prohibidas que se pueden utilizar. La disposición más común para las celdas en tándem es crecerlas monolíticamente de manera que todas las celdas crecen como capas en el sustrato y las uniones túnel conectan las celdas individuales. 
La eficiencia máxima para un tándem de dos uniones bajo el espectro AM1.5G y sin concentración del sol es de $47 \%$. Para una máxima eficiencia, la celda superior tiene una banda prohibida de 1,63 eV y la celda inferior tiene una banda prohibida de 0,96 eV. La Figura 4 muestra resultados adicionales en celdas tándem en función del número de bandas prohibidas y utilización de métodos de cálculo. La respuesta en todo caso tiene que ver adicionalmente con la composición de capas y otros parámetros. Es importante, sin embargo, los altos valores de eficiencia obtenidos, que invitan a profundizar en estos estudios.

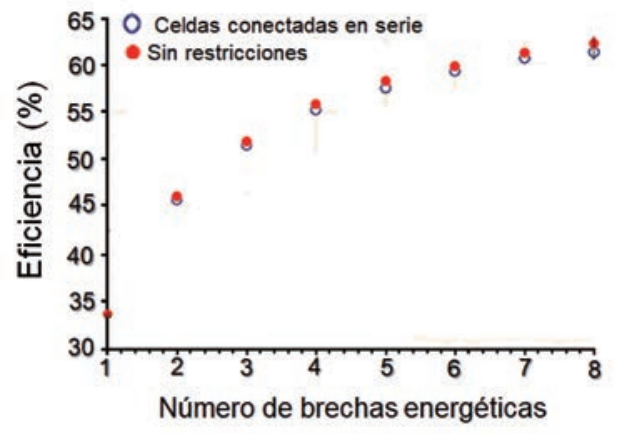

Figura 4. Eficiencia de una pila de celdas solares como función del número de bandas prohibidas.

El espectro utilizado aquí es el espectro directo (AM 1.5 G), donde se excluye la radiación difusa

(Bremner, Levy, \& Honsberg, 2008)

Adicionalmente, se presenta la Tabla 2, que agrupa en forma comparativa, diferentes tecnologías fotovoltaicas y que, de igual manera, estimulan la eficiente captura y utilización de energía solar con fines múltiples y variados. 
Tabla 2. Comparación de tecnologías fotovoltaicas (Sandoval-Ruiz, 2020)

\begin{tabular}{|c|c|c|c|c|}
\hline Clase & $\begin{array}{c}\text { Materiales } \\
\text { Fotovoltaicos }\end{array}$ & $\begin{array}{l}\text { Eficiencia } \\
(\%)\end{array}$ & Tecnología & Características \\
\hline $\mathrm{I}^{-S i_{C}} \mathrm{Si}$ & $\begin{array}{l}\text { monocritalino } \\
\text { Si policristalino }\end{array}$ & $\begin{array}{l}16 \\
14\end{array}$ & $\begin{array}{l}\text { Si cristalino } \\
\text { Base Oblea }\end{array}$ & $\begin{array}{l}\text { Efic. en Lab. } \\
26,7 \% \text {. Módulos } \\
\text { rígidos }\end{array}$ \\
\hline $\begin{array}{l}\text { I-película } \\
\text { delgada }\end{array}$ & $\begin{array}{c}\text { GaAs } \\
\text { CIGS } \\
\text { Perovskita (Pb) }\end{array}$ & $\begin{array}{l}28,8 \\
22,6 \\
22,7\end{array}$ & Película fina & Módulos rígidos \\
\hline $\begin{array}{l}\text { III-Tecnologías } \\
\text { emergentes }\end{array}$ & $\begin{array}{c}\text { MJ } 2 \text { uniones } \\
\text { MJ } \geq 4 \text { uniones } \\
\text { PerovskitaBaZrTiS } 3 \\
\text { Si + Concent. Ópt }\end{array}$ & $\begin{array}{c}39,2 / 44,4 \\
40,7 / 47,7 \\
38,7 \\
44,1\end{array}$ & $\begin{array}{l}\text { Multiunión } \\
\text { Multiunión } \\
\text { Mat. Hibridos } \\
\text { Lentes Óptics }\end{array}$ & $\begin{array}{c}\text { Tándem } \\
\text { Alto coef. Abs. }\end{array}$ \\
\hline
\end{tabular}

\section{Almacenamiento de energía}

Una alternativa energética a fuentes altamente contaminantes al ambiente, la constituye la electroquimienergía, con sus rutas de captura, conversión, almacenamiento, suministro, de energía desde fuentes no contaminantes primarias y secundarias. Las ramas científicas de la nanociencia, nanoelectroquímica y nanoelectrocatálisis juegan actual- mente un papel estelar, en nuevos y avanzados desarrollos en este campo. En esta sección se tratará brevemente del almacenamiento de energía en celdas y baterías, las cuales se listan en la Tabla 3 y las aplicaciones más comunes, según su tipo, en Tabla 4. Se presenta una reseña de celdas plomo-ácido y ion litio, por su estelaridad (Bisquert, 2005; Olabi, et al., 2020; Datta, Mukherjee \& Chiu, 2021) 
Tabla 3. Cuadro comparativo de acumuladores

(Bisquert, 2005)

\begin{tabular}{cccccc}
\hline TIPO & $\begin{array}{c}\text { Energía/Peso } \\
(\mathrm{Wh} / \mathrm{kg})\end{array}$ & $\begin{array}{c}\text { Voltaje/Elemento } \\
(\mathrm{V})\end{array}$ & $\begin{array}{c}\mathbf{N}^{\circ} \text { de } \\
\text { Recargas }\end{array}$ & $\begin{array}{c}\text { Tiempo de } \\
\text { Carga } \\
(\mathrm{h})\end{array}$ & $\begin{array}{c}\text { Autodescarga } \\
\text { por mes } \\
(\%)\end{array}$ \\
\hline $\mathrm{Pb}$ & $30-40$ & 2 & 1000 & $8-16$ & 5 \\
$\mathrm{Ni}-\mathrm{Fe}$ & $30-55$ & 1,2 & 10000 & $4-8$ & 10 \\
$\mathrm{Ni}-\mathrm{Cd}$ & $48-80$ & 1,25 & 500 & $10-14$ & 30 \\
$\mathrm{NiMn}$ & $60-120$ & 1,25 & 1000 & $2-4$ & 20 \\
Li-lón & $110-160$ & 3,7 & 4000 & $2-4$ & 25 \\
Li-Po & $100-130$ & 3,7 & 5000 & $1-1,5$ & 10 \\
\hline
\end{tabular}

La batería Plomo-Ácido $\left(\mathrm{Pb}_{(\mathrm{s})}\right)^{\prime}$ $\begin{array}{llll}\mathrm{PbSO}_{4} & (\mathrm{~s})^{\prime} & \mathrm{H}_{2} \mathrm{SO}_{4(\mathrm{ac})} / \mathrm{PbSO}_{4(\mathrm{~s})} /\end{array}$ $\left.\mathrm{PbO}_{2(\mathrm{~s})} / \mathrm{Pb}_{(\mathrm{s})}\right)$ (Villarreal-Archila, Serrano-Figueroa, Quiroga-Rojas, 2021) es el sistema de baterías secundarias más utilizado y económico. Su gran versatilidad y reversibilidad le permiten aplicaciones variadas (baterías estacionarias, arranque-iluminación, tracción, portátiles, etc.). Las actuales baterías plomo-ácido reguladas con válvulas, no requieren mantenimiento alguno. El desarrollo de baterías para tracción de vehículos ha sido de gran interés estas últimas dé- cadas, debido a las mejoras ambientales (eliminación de ruido y contaminación), sustitución de combustibles fósiles, eliminación de vibraciones, conducción más fácil, etc.

Se han desarrollado procesos ecológicos hidrometalúrgicos que permiten tratar materias primas convencionales, como son las baterías, junto con otros residuos industriales o materiales secundarios de plomo o incluso concentrados de sulfuro de plomo, para el rescate y reciclado de materiales. 


\section{Tabla 4. Clasificación de celdas/baterías en relación a su tamaño y aplicaciones}

(Mantell, 2021; Li et al., 2021)

\begin{tabular}{ccc}
\hline TIPO & $\begin{array}{c}\text { ENERGÍA } \\
\text { SUMINISTRADA } \\
\text { (Wh) }\end{array}$ & APLICACIONES \\
\hline $\begin{array}{c}\text { Celdas/Baterías } \\
\text { Miniaturizadas }\end{array}$ & $0,1-2$ & $\begin{array}{c}\text { Relojes Eléctricos, Microelectrónica } \\
\text { Implantes Médicos }\end{array}$ \\
\hline $\begin{array}{c}\text { Celdas/Baterías } \\
\text { para equipos portátiles }\end{array}$ & $2-100$ & $\begin{array}{c}\text { Linternas, Luces, Juguetes, Herramientas, } \\
\text { Electrónicos Portátiles (radio, TV, } \\
\text { computadora, teléfono) }\end{array}$ \\
\hline $\begin{array}{c}\text { Baterías SLI (inicio, } \\
\text { alumbrado, encendido) }\end{array}$ & $100-600$ & $\begin{array}{c}\text { Vehículos y maquinaria agrícola } \\
\text { Batería de Tracción } \\
\text { de Vehículos }\end{array}$ \\
\hline $\begin{array}{c}\text { Baterías Estacionarias } \\
(20-630) \times 10^{3}\end{array}$ & $\begin{array}{c}\text { Montacargas, Locomotoras, Submarinos } \\
(0,25-5) \times 10^{6}\end{array}$ & $\begin{array}{c}\text { Sistemas de emergencia, almacenamiento } \\
\text { de energía local, Redes de } \\
\text { estaciones remotas }\end{array}$ \\
\hline $\begin{array}{c}\text { Baterías de nivelación } \\
\text { de cargas }\end{array}$ & $(5-100) \times 10^{6}$ & $\begin{array}{c}\text { Regulación de máximos y mínimos } \\
\text { de consumo energético en ciudades }\end{array}$ \\
\hline
\end{tabular}

La sociedad demanda continuamente baterías capaces de desarrollar más energía con menor peso y volumen, económicas, seguras, amigables al ambiente y reciclables. Las baterías con especies de inserción/intercalación de litio son capaces de desarrollar altas energías específicas. Desarrollo más reciente lo constituye las baterías de ion litio (utiliza dos compuestos de inserción como electrodos de la batería, son compuestos litiados estables al aire), Ej. de esta batería lo constituye el sistema $\mathrm{LiC}_{\mathrm{o}} \mathrm{O}_{2}-\mathrm{Li}_{\mathrm{y}} \mathrm{C}_{2}$ (Figura 5) (energía específica, hasta $150 \mathrm{Whkg}^{-1}$; ciclabili- dad hasta 3000 recargas y eficiencia del $90 \%$ ) (Chen, Zhang, Xing, Chou, \& Tang, 2021). Se avanza en las investigaciones en electrodos positivos y negativos, nuevos materiales (óxidos y aleaciones), nano investigaciones por esta vía (Ventosa, 2021; Steve-Adell, Gil-Agusti, Saenz de Zaitegui, Quijano-Lòpez, \& GarcìaPellicer, 2020), han mostrado capacidad específica de $1030 \mathrm{AhKg}^{-1}$, capacidad reversible de almacenaje de litio 600-700 $\mathrm{AhKg}^{-1}$, entre otros valores (Li et al., 2021; Poizot, LarueIle, Grugeon, Dupont, \& Tarascon, 2000). El interés por baterías para ve- 
hículos eléctricos se ha centrado en ion Litio, ello por un relativo alto voltaje, potencia específica cercana a
$300 \mathrm{WhKg}^{-1}$, volumen y peso, relativamente menores, ciclabilidad en 1200.

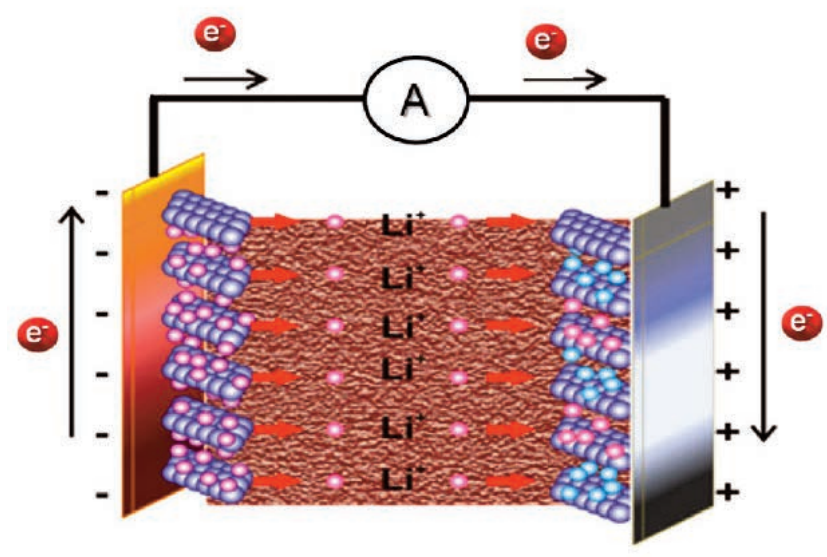

Figura 5. Descripción de un modelo de celda de ion-Litio. (-) Material carbonado. (+) $\mathrm{LiCoO}_{2}$

Baterías redox de vanadio con flujo: Las baterías redox con flujo (BRF) y, en particular, la batería redox de Vanadio con flujo (BRVF) (Márquez et al., 2018; Ponce de León et al., 2006) están actualmente en un estado avanzado de desarrollo, incentivado por la gran variedad e importancia previstas de sus aplicaciones y necesidades prácticas por el desarrollo de almacenadores energéticos. Las baterías para almacenamiento a gran escala en redes requieren de larga vida, alta durabi- lidad en ciclos carga/descarga, alta y sostenidaeficiencia, rápida respuesta a cambios y un razonable costo capital. La potencia y la capacidad energética de la batería redox de Vanadio con flujo pueden ser parámetros separados: la potencia del sistema está determinada por el número de celdas en el arreglo y el tamaño de los electrodos, mientras que la capacidad de almacenamiento energético es dependiente de la concentración y el volumen del electrolito en el sistema. Todas ellas, 
son características favorables para ese fin $y$, aunque adolece de algunas limitaciones en otras aplicaciones como almacenamiento no estacionario, hay actualmente un intenso estudio, que pudiese conducir a resultados favorables. Este artículo se refiere al tópico de actualidad de los vehículos eléctricos y el papel de las baterías redox con flujo, en particular la batería redox de Vanadio y sus aportes en forma conjunta con energías renovables, por accesibilidad, almacenamiento y suministro permanente de esta energía, el saneamiento ambiental y una progresiva reducción de costos. La nanociencia, con sus ramas nanoelectroquímica y nanoelectrocatálisis, están Ilamadas a conseguir el incremento en el almacenamiento energético en estas baterías, situación primordial por una solución.

El acoplamiento a fuentes renovables de energía, de dispositivos almacenadores, amplía sus posibilidades de uso en condiciones de emergencia, limitaciones y/o accesibilidad. actualmente se desarrollan baterías para el almacenamiento energético a gran escala, en esos casos se requiere de baterías de alta durabilidad, que soporten altos ciclos carga-descarga (Olabi et al., 2020), alta eficiencia, rápida respuesta, de costo razonable y funcionamiento ecológico. El sistema redox de vanadio es una interesante alternativa energética, para el almacenaje de energía y su uso como fuente secundaria de suministro (Figura 6) (Pugach, Vyshinsky, \& Bischi, 2019). Las baterías redox de vanadio son de bajo costo, de relativamente bajo impacto ambiental, alto ciclo de vida, reacciones redox simples y reversibles, funcionamiento a bajas temperaturas, alta eficiencia energética y pueden ser recargadas instantáneamente (por cambio del medio electrolítico) o eléctricamente en corto tiempo. Adicionalmente, la celda redox de vanadio puede funcionar como celda de combustible, en la medida en que los electrolitos sean alimentados en forma permanente pues se tendría de vuelta un suministro también permanente de energía. 


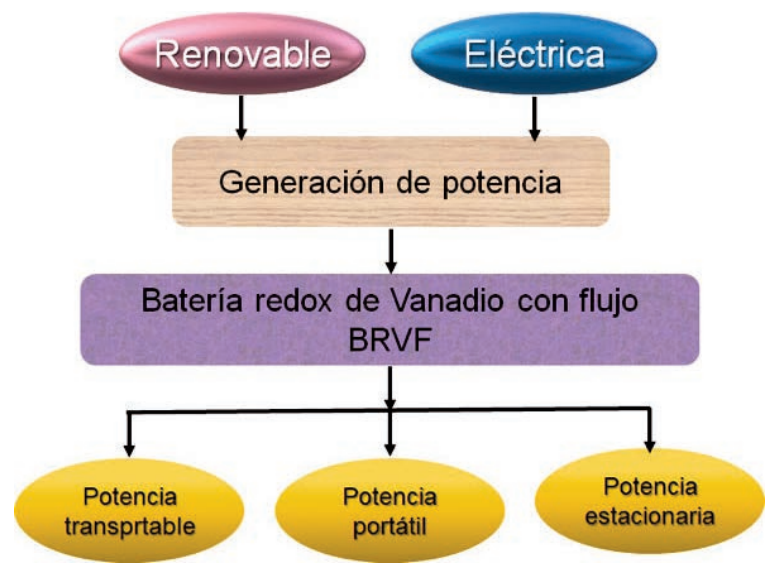

Figura 6. Aplicaciones de Batería Redox de Van Flujo

(Márquez, et al. 2021)

Las celdas y baterías redox recargables y con flujo, están actualmente bajo intenso estudio (de hecho, existen ya algunas comerciales) debido a sus propiedades y características que las hacen apropiadas para conversión, almacenamiento y suministro de energía, cuando esta es requerida.

\section{Celdas (pilas) de combustible}

Las pilas de combustible son dispositivos en los que la energía de una reacción química se transforma en electricidad. No funcionan como las baterías convencionales que se gastan y deben sustituirse o recargarse.
En este caso mientras se inyecte combustible y oxidante, el sistema continúa funcionando. Su funcionamiento es el opuesto al de electrólisis; la reacción del hidrógeno y el oxígeno para formar agua produce en este caso electricidad. Están formadas por un ánodo y un cátodo separados por un fluido de electrolito conductor. En el ánodo se inyecta el combustible hidrógeno, mientras que en el cátodo se introduce el oxidante, aire u oxígeno. El resultado es una mayor eficiencia energética, entre un $30 \%$ y un $40 \%$, que en un motor térmico convencional que utilice combustibles fósiles. 
Desde el punto de vista del consumo de energía puede incrementarse la eficiencia energética en : (Green, 2002; De Bastiani et al., 2021; Li et al., 2020)

-Los procesos industriales.

-El transporte.

-Los servicios.

-Los hogares.

-La agricultura, la pesca, etc.

En el ámbito de la industria, es posible realizar avances significativos en amplios sectores, dentro de la estrategia de eficiencia energética.

En cuanto a los aspectos técnicos, centrándose en los vehículos terrestres con motor de explosión, se puede apreciar que son muy ineficientes. De la energía total del combustible, sólo llega a las ruedas una pequeña fracción (13\%) el resto se disipa en forma de calor, en el motor y la transmisión y, aún de esta energía, una parte sustancial se pierde en el rozamiento con el suelo y el aire. Además, se debe tener en cuenta, que la mayor parte de la energía resultante se emplea en desplazar la masa del vehículo. Las estrategias seguidas para reducir el consumo inciden en la eficiencia de los moto- res, la aerodinámica, el peso total y en los neumáticos. Ya existen en el mercado vehículos híbridos que funcionan de modo mixto con un motor de combustión interna y otro eléctrico aumentando la eficiencia. En algunos casos recuperan incluso la energía cinética que se pierde en el frenado. La fuente última de energía es el motor de combustión, pero existen dos tipos: en paralelo y en serie. En el primero ambos motores impulsan el vehículo y en el segundo el motor térmico genera la electricidad que se almacena en baterías que luego alimentan el motor eléctrico (Olabi, Wilberforce, \& Abdelkareem, 2020). Otra alternativa son los vehículos impulsados por hidrógeno, con una eficiencia de un $22 \%$ superior a los equivalentes que utilizan gasolina (Wang, Chen, Ruiz-Dìaz, \& Wang, 2020). El peso es otro factor muy importante: sin embargo, los intentos de reducirlo, a pesar de los éxitos logrados, chocan a menudo con problemas de seguridad. El empleo de nuevos materiales (nuevas aleaciones y polímeros) pueden ser la solución al problema de compatibilizar ambas. La eficiencia, de una celda de combustible está expresada en la ecuación (4): 


$$
\begin{gathered}
\theta=\frac{\text { Energía Útil }}{\Delta H}=\frac{\text { Energía Eléctrica producida }}{\text { Energía térmica producida durante la reacción química }} \\
\theta=83 \%\left(C \mathrm{C} \text { de } \mathrm{H}_{2} \text { y } \mathrm{O}_{2} a 25^{\circ} \mathrm{C}\right)
\end{gathered}
$$

Tabla 5. Potencial y Eficiencia en Energía para algunas reacciones en Celdas de Combustible

(Wang, Chen, Ruiz-Dìaz, \& Wang, 2020)

\begin{tabular}{ccc}
\hline Reacción & E (V) & (\%) \\
\hline $\mathrm{H}_{2}+\frac{1}{2} \mathrm{O}_{2} \rightarrow \mathrm{H}_{2} \mathrm{O}$ & 1,229 & 83 \\
\hline $\mathrm{CH}_{4}+2 \mathrm{O}_{2} \rightarrow \mathrm{CO}_{2}+2 \mathrm{H}_{2} \mathrm{O}$ & 1,060 & 92 \\
\hline $\mathrm{CH}_{3} \mathrm{OH}+3 / 2 \mathrm{O}_{2} \longrightarrow \mathrm{CO}_{2}+2 \mathrm{H}_{2} \mathrm{O}$ & 1,222 & 93 \\
\hline $\mathrm{CO}+1 / 2 \mathrm{O}_{2} \longrightarrow \mathrm{CO}_{2}$ & 1,333 & 91 \\
\hline
\end{tabular}

Entre las aplicaciones futuras de las celdas de combustible se pueden citar (O’M Bockris \& Reddy AKN, 2002):

- Dispositivos portátiles para alimentar aparatos de todo tipo: ordenadores, videocámaras, teléfonos móviles, etc., sustituyendo las baterías tradicionales.

- El transporte, especialmente la automoción.

- Aplicaciones especiales: militares y viajes espaciales.

- Abastecimiento energético en aplicaciones fijas: áreas residenciales, hospitales, empresas, etc.
Las ventajas de las celdas de combustible son:

1. Elevada eficiencia energética, entre el $30 \%$ y el $90 \%$

2. Emisiones de contaminantes muy inferiores a las que generan los combustibles fósiles. En el caso de utilizar hidrógeno puro sólo se producen $\mathrm{H}_{2} \mathrm{O}$, energía y calor. Es de hacer notar que para generar éste, sí se producen emisiones de $\mathrm{CO}_{2}$ y otros contaminantes, pero en un nivel muy inferior que si se utilizaran como combustibles en sistemas convencionales. 
3. Bajo nivel de ruido producido en su funcionamiento

4. Modularidad.

5. Alta densidad energética.

6. Operan a bajas temperaturas y presiones, comparadas con los motores convencionales: entre $80{ }^{\circ} \mathrm{C}$, y $1000{ }^{\circ} \mathrm{C}$, en comparación con los $2500{ }^{\circ} \mathrm{C}$ de un motor convencional.

7. Flexibilidad en la localización de su instalación

8. Permiten la cogeneración, alcanzando niveles de eficiencia sobre el $90 \%$.

19. Admiten diversos combustibles: gas natural, metanol, etc.

10. No se reemplazan al agotarse, nes necesario un largo periodo de recarga como les ocurre a las baterías eléctricas, basta con inyectar más combustible.
11. Rápida respuesta: permiten obtener más energía si se inyecta más combustible.

El hidrógeno usado en las pilas de combustible puede ser producido a través del reformado de gas natural o la electrólisis del agua a partir de energía obtenida de fuentes no renovables. El reto actual es hacer rentable su obtención, a partir de fuentes renovables como la energía eólica o la solar fotovoltaica o térmica. Su implantación a gran escala, si se consiguen reducir los costos, podría ayudar a reducir la dependencia actual de los combustibles fósiles. A continuación, se hará una breve reseña de las celdas de combustible, PEMFC y DMFC, actualmente están siendo incorporadas como fuentes energéticas en vehículos eléctricos.

Tabla 6. Tecnología de Celdas de Combustible

(Arenal- Mendoza, Ángeles-Jiménez, \& Gonzàlez, 2010)

\begin{tabular}{ccc}
\hline TIPO & $\begin{array}{c}\text { EFICIENCIA } \\
(\%)\end{array}$ & $\begin{array}{c}\text { TEMPERATURA } \\
\text { DE OPERACIÓN } \\
\left({ }^{\circ} \mathrm{C}\right)\end{array}$ \\
\hline $\begin{array}{c}\text { Membrana de Intercambio Protónico } \\
\text { (PEMFC) }\end{array}$ & 40 & 50 \\
\hline Celda de Metanol Directo (DMFC) & 40 & 80 \\
\hline Alcalina (AFC) & $50-60$ & 80 \\
\hline Celda de ácido fosfórico (FAFC) & 40 & 200 \\
\hline Celda de Carbonato fundido (MCFC) & 50 & 650 \\
\hline Celda de Óxido Sólido (SOFC) & $45-65$ & 800 \\
\hline
\end{tabular}


Celda de Membrana de Intercambio Protónico (PEMFC): Operan a relativamente bajas temperaturas $\left(80^{\circ} \mathrm{C}\right)$. Tienen alta densidad de potencia. Pueden variar su salida rápidamente para atender cambios en la demanda de potencia. Son apropiadas para aplicaciones (tales como en automóviles) donde un rápido encendido es requerido. Son apropiadas (DOE) para vehículos ligeros, edificaciones, y otras aplicaciones menores (Figura 7). La membrana de intercambio protónico es una lámina plástica del- gada $\left(\right.$ nafion ${ }^{\circledR}$ ) que permite el paso de iones hidrógeno. La membrana es cubierta en ambos lados con partículas metálicas altamente dispersas (Pt-catalizador activo). El electrolito utilizado es un polímero sólido orgánico, ácido poli-perfluorosulfonico. Este tipo de celda es sensible a la presencia de impurezas en el combustible. Su rango de salida es 50 a 250 kW. Se ha logrado reducir la carga de platino y se realizan esfuerzos por optimizar el electrolito y placas bipolares.

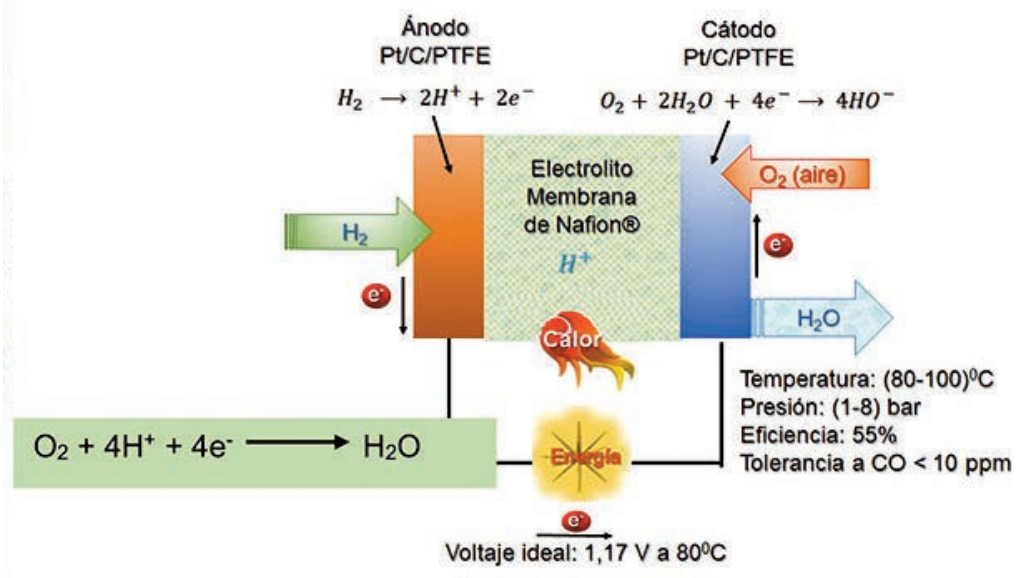

Figura 7. Celda de Combustible de Membrana de Intercambio protónico (PEM) (Barbir, 2005; Asensio, 2020) 
Celda de Combustible de Metanol (DMFC) Utiliza una membrana polimérica como electrolito. El ánodo catalizador extrae el hidrógeno del metanol líquido, eliminando la necesidad de un reformador de combustible. La eficiencia es del orden del $40 \%$ y tipicamente opera entre
50 y $100^{\circ} \mathrm{C}$. La celda es atractiva para aplicaciones pequeñas y medianas, celulares, laptops, etc. Con el incremento en la temperatura se obtiene eficiencias más altas.

La Tabla 7 muestra las reacciones que ocurren en la celda.

Tabla 7.- Tecnología de Celdas de Combustible

\begin{tabular}{lr}
\hline Electrodo & Reacción \\
\hline Ánodo & $\mathrm{CH}_{3} \mathrm{OH}(a c)+\mathrm{H}_{2} \mathrm{O}(l) \rightarrow \mathrm{CO}_{2}(g)+6 \mathrm{H}^{+}(a c)+6 e^{-}$ \\
\hline Cátodo & $6 \mathrm{H}^{+}(a c)+\frac{3}{2} \mathrm{O}_{2}(g)+6 e^{-} \rightarrow 3 \mathrm{H}_{2} \mathrm{O}(l)$ \\
\hline & Celda: $\quad \mathrm{CH}_{3} \mathrm{OH}(a c)+\frac{3}{2} \mathrm{O}_{2}(g) \rightarrow \mathrm{CO}_{2}(g)+\mathrm{H}_{2} \mathrm{O}(l)$ \\
\hline
\end{tabular}

Las Celdas de combustible regenerativas son atractivas como forma cíclica de generación de potencia. El agua es separada en hidrógeno y oxígeno por un electrolizador alimentado con energía renovable, estos gases alimentan a la celda de combustible, que genera electricidad, calor y agua. El agua es entonces recirculada al electrolizador y el proceso comienza de nuevo.

\section{Combustible hidrógeno: Producción desde fuentes energéticas renova- bles}

El hidrógeno es una fuente secundaria de energía. Se presenta como una manera adecuada de almacenaje, en forma de energía química. Es obtenido por consumo de fuentes primarias de energía, renovables y no renovables, y a partir de ciertas materias primas como el agua, la biomasa, hidrocarburos y otros combustibles. 
El hidrógeno: se obtiene mediante electrólisis del agua, utilizando electricidad procedente de fuentes renovables; por esta vía se genera energía con poca o ninguna contribución de dióxido de carbono a la atmósfera. Actualmente se avanza en el desarroIlo de medios eficientes de almacenamiento de energía y, en particular, del hidrógeno y ello, sumado a otras exigencias vigentes tales como facilidad de transporte, nula o baja producción de contaminantes en su uso, aceptabilidad, reservas ilimitadas, combustión completa, eficiencia y versatilidad de usos (combustible, motores, turbinas, pilas de combustible, etc.), y el hecho, de actuales exigencias en la protección ambiental, así como el progresivo y cercano agotamiento de combustibles fósiles, avalan el creciente interés por su producción. Son variadas las vías actuales de producción de hidrógeno, desde fuentes energéticas no renovables, contaminantes (petróleo, gas, carbón, nuclear) y fuentes renovables como (solar, eólica, hidroeléctrica, marina, geotérmica, biomasa). La producción puede realizarse principalmente con luz, calor, electricidad y energía química. Un hecho también de gran importancia en la ob- tención de hidrógeno a partir del agua, lo constituye la regeneración (recuperación) de ésta, cuando el hidrógeno es consumido (Dincer, 2012; Casadevall, Call, Codolá, Acuña-Pares, \& Lloret-Fillol, 2016; Tuller, 2017; Willkomm et al., 2016)

Los requerimientos actuales a nivel mundial, en los campos energético, económico, salud, comunicación, seguridad, ambiente, servicios y bienestar comunitario, urgen por el acceso sin limitaciones al recurso energético. En la práctica, ello se traduce, en la disposición general sin restricciones, en primera instancia del recurso energético, desde fuentes seguras, disponibles, ilimitadas, accesibles, variadas, no contaminantes y económicas. De las fuentes disponibles, el hidrógeno cumple con buena parte de estas exigencias y ello explica la creciente actividad científico-técnica, los nuevos desarrollos y nuevas aplicaciones de este recurso. El combustible hidrógeno es considerado un eficiente y limpio transporte de energía, que solamente produce agua como un subproducto de su combustión (El-Shafie, Kambara, \& Hayakawa, 2019; Dunn, 2007). La eficiencia de producción 
de hidrógeno, del agua y energías renovables se ubica entre un $40-70$ \% (Tabla 8). La Tabla 9 nos presenta parámetros tales como los factores de contenido de hidrógeno, de descontaminación, impacto ambiental de hidrógeno y combustibles fósiles, para interrelación.

Tabla 8. Eficiencia de Tecnologías de Hidrógeno-Renovable (Willkomm et al.,2016)

\begin{tabular}{cccc}
\hline Tecnología & $\begin{array}{c}\text { Stock de } \\
\text { alimentación }\end{array}$ & $\begin{array}{c}\text { Eficiencia } \\
(\%)\end{array}$ & Estado \\
\hline $\begin{array}{c}\text { Electrolizador } \\
\text { Alcalino }\end{array}$ & $\mathrm{H}_{2}+$ electricidad & $50-60$ & Comercial \\
\hline $\begin{array}{c}\text { Electrolizador } \\
\text { PEMFC }\end{array}$ & $\mathrm{H}_{2}+$ electricidad & $55-70$ & Término corto \\
\hline $\begin{array}{c}\text { Celda de Electrolisis } \\
\text { de óxido sólido }\end{array}$ & $\begin{array}{c}\mathrm{H}_{2}+\text { electricidad } \\
+ \text { calor }\end{array}$ & $40-60$ & Término medio \\
\hline $\begin{array}{c}\text { Escisión } \\
\text { Termoquímica } \\
\text { del agua }\end{array}$ & $\mathrm{H}_{2}+$ calor & $\mathrm{NA}$ & Término largo \\
\hline $\begin{array}{c}\text { Escisión } \\
\text { Fotoelectroquímica } \\
\text { del agua }\end{array}$ & $\mathrm{H}_{2}+$ luz solar & 12,4 & Término largo \\
\hline
\end{tabular}

Tabla 9. Factor de contenido de hidrógeno (FCH),

Factor descontaminante (FD), Factor de impacto ambiental (FIA) de hidrógeno y otros combustibles fósiles (Dincer \& Acar, 2015).

\begin{tabular}{ccccc}
\hline Combustible & Carbón & Petróleo & Gas Natural & Hidrógeno \\
\hline FCH o FD & 0 & 0,1 & 0,38 & 1,0 \\
\hline FIA & 3,35 & 3,2 & 2,5 & 0,0 \\
\hline
\end{tabular}

El método de electrolisis de agua puede limitarse a los siguientes tipos: electrolito alcalino, membrana de intercambio protónico y electrolizador de óxido sólido. En la Tabla 10 se lis- tan, especificaciones típicas de los métodos tecnológicos de electrólisis del agua. Se han desarrollado electrolizadores de baja temperatura y tienen eficiencias de $56 \%-73 \%$ en 
condiciones de (70,1 -53,4 kWh.kg-1, $\mathrm{H}_{2}$ a $1 \mathrm{~atm}$ y $25^{\circ} \mathrm{C}$ ). Los sistemas de electrólisis alcalino son los más co- munes y el sistema de electrolisis de óxido sólido es el más eficiente eléctricamente, aún bajo desarrollo.

Tabla 10. Especificaciones de electrolizadores Alcalino, Membrana de Intercambio Protónico (PEM) y Óxido Sólido (SOE) (Bhandari, Trudewind, \& Zapp, 2014)

\begin{tabular}{|c|c|c|c|}
\hline Especificaciones & Alcalino & PEM & SOE \\
\hline $\begin{array}{l}\text { Madurez de la } \\
\text { Tecnología }\end{array}$ & Estado del Arte & Demostración & $R \& D$ \\
\hline $\begin{array}{l}\text { Temperatura de la } \\
\text { Celda, }{ }^{\circ} \mathrm{C}\end{array}$ & $60-80$ & $50-80$ & $900-1000$ \\
\hline $\begin{array}{c}\text { Presión de la Celda } \\
\text { bar }\end{array}$ & $<30$ & $<30$ & $<30$ \\
\hline $\begin{array}{c}\text { Densidad de } \\
\text { Corriente } \mathrm{A} / \mathrm{cm}^{2}\end{array}$ & $0,2-0,4$ & $0,6-2,0$ & $0,3-1,0$ \\
\hline Voltaje de Celda, V & $1,8-2,4$ & $1,8-2,2$ & $0,95-1,3$ \\
\hline $\begin{array}{c}\text { Densidad de } \\
\text { Potencia } \mathrm{W} / \mathrm{cm}^{2}\end{array}$ & Hasta 1,0 & Hasta 4,4 & - \\
\hline $\begin{array}{l}\text { Eficiencia en } \\
\text { Voltaje, \% }\end{array}$ & $62-82$ & $67-82$ & $81-86$ \\
\hline $\begin{array}{l}\text { Consumo de energía } \\
\text { de sistema } \\
\text { específico }\end{array}$ & $4,5-7,0$ & $4,5-7,5$ & $2,5-3,5$ \\
\hline
\end{tabular}

Son variados los campos científicotécnicos de atención a los requerimientos energéticos, dentro de ellos, el campo electroquímico, en sintonía con el catalítico y la nanociencia, muestran una gran versatilidad para el tratamiento de esos requerimientos. Hay un avance permanente y sostenido, en los estudios, diseños, mejoras, aplicaciones, en este campo y otros, y es de esperar que, en un tiempo razonable, el planeta en su totalidad disfrute, sin restricciones, la solución a esta situación de actual emergencia. En electroquímica, se trata con fuentes energéticas renovables, poco o no contaminantes, solar (directa, indirecta, difusa, térmica), eólica, hidroeléctrica, marina, geotérmica; con diseños sencillos, modificables, evolutivos y aplicables 
Producción de hidrógeno en celdas fotoelectroquímicas

- Celda fotoelectroquímica que utiliza un fotoelectrodo estructurado en capas e incorpora un catalizador coloide de platino (ec. 5)

$$
2 \mathrm{H}_{2} \mathrm{O} \frac{\mathrm{h} \bullet}{\text { Catalizdor }} \rightarrow 2 \mathrm{H}_{2}+\mathrm{O}_{2}
$$

- Celda Tándem de multiuniones (Ho, Thogiti, Lee, \& Kim, 2017; Willkomm, J.; Orchard, KL.; Reynal, A., et al.; Yanagida, Onozawa, Mitsuhiko, Kazuhiro, \& Sugihara, 2010), la cual es una celda de semiconductores, con brechas energéticas (band gaps) que van disminuyendo sucesivamente. Cada semiconductor absorbe una porción diferente del espectro solar y como consecuencia se producen altas eficiencias (> $30 \%$ ). Existen además investigaciones en desarrollo, por ejemplo, con aleaciones II-VI, incorporando impurezas de tierras raras. El sistema es bipolar para generar el potencial necesario; los dos polos son a su vez divididos en una serie de multiuniones para absorber una proporción del espectro solar más grande. La electrólisis ocurre por medio de electrocatalizadores, $\mathrm{Pt}_{\text {negro }}$ y $\mathrm{RuO}_{2}$ (ec. 6).

$$
2 \mathrm{H}_{2} \mathrm{O} \stackrel{n v+\text { catalızaaor Tanaem }}{\longrightarrow} 2 \mathrm{H}_{2}+\mathrm{O}_{2}
$$

En el caso de funcionamiento de una celda fotoelectroquímica sensibilizada para la fotoelectrólisis del agua, la luz es absorbida por el colorante y los electrones inyectados al semiconductor. La reacción de oxi- dación ocurre en la interfaz colorante - electrolito. El sistema lo componen semiconductores nano estructurados (para incrementar el área real) - sensibilizador - electrolito (ec. 7).

$$
2 \mathrm{H}_{2} \mathrm{O} \longrightarrow 2 \mathrm{~h}_{2}+\mathrm{O}_{2}
$$

Fotoelectrólisis de agua sobre una solución sólida fotocatalizadora. (i) el Fotocatalizador absorbe más ener- gía fotónica (solar) que la brecha energética del material y genera pares electrón-huecos fotoexitados 
en la masa. (ii) las cargas fotoexitadas se separan y migran a los diferentes sitios de la superficie fotocatalítica sin sufrir recombinación y (iii) el agua es reducida y oxidada por electrones y huecos para producir hidrógeno y oxígeno respectivamente (ec. 8).

$$
2 \mathrm{H}_{2} \mathrm{O} \longrightarrow 2 \mathrm{hv+ \text {Catalizador } + \text { Co-Catalizador }} \longrightarrow 2 \mathrm{H}_{2}+\mathrm{O}_{2}
$$

El hidrógeno electrolítico convenientemente almacenado, ya sea como gas comprimido, líquido a bajas temperaturas o sólido bajo la forma de hidruro metálico, puede reconvertirse a electricidad en celdas de combustible durante las horas de mayor consumo o períodos nocturnos o de ausencia de viento y transportarse al centro de consumo donde su combustión térmica produce calor y agua, aunque también se genera algo de NOx si se utiliza aire como comburente o, alternativamente, alimentar a celdas de combustible produciendo directamente electricidad y agua, que retorna al ambiente, sin emisión de contaminantes. De este modo, el ciclo del hidrógeno constituye un sistema cerrado ya que el combustible se regenera. El hidrógeno también se puede usar directamente en quemadores o motores, produciendo calor por combustión limpia, o convertir directamente su energía química en electricidad en celdas de combusti- ble, en un proceso de alta eficiencia (Kruse, 2011). Puesto que el hidrógeno no se encuentra libre en la naturaleza, se debe gastar energía para producirlo, tal como en el caso de la electricidad.

\section{Comburente oxígeno}

En los últimos años, se han producido avances importantes a nivel mundial con el desarrollo de celdas de combustible de hidrógeno/oxígeno que emplean la nueva tecnología de electrolito de polímero sólido, con la cual se alcanzan altas eficiencias de conversión y densidades de potencia. Sin embargo, existen todavía pérdidas de energía importantes asociadas a problemas de electrocatálisis de las reacciones electródicas, que disminuyen la eficiencia de conversión a (50-60) \%. Uno de los inconvenientes en las celdas de combustible que operan a bajas temperaturas y a altas densidades de potencia, se debe al alto so- 
brepotencial de la reacción de reducción de oxígeno (RRO).

Por ello, para reducir las pérdidas de energía asociadas, se requiere del desarrollo de materiales de electrodos con estructuras superficiales de alta actividad catalítica que permitan minimizar las pérdidas de energía relacionadas con los sobrepotenciales de electrodo, particularmente los correspondientes a la reducción de oxígeno, y así conducir los procesos de conversión de energía a velocidad y eficiencia máximas.

Las celdas de combustible de baja temperatura necesitan electrocatalizadores para acelerar las reacciones involucradas en los procesos electródicos, principalmente la reacción catódica. En una celda de combustible de hidrógeno/oxígeno, la reacción catódica de electrorreducción de oxígeno es de suma importancia por el consumo energético involucrado, que es aproximadamente cuatro veces mayor que el de la reacción anódica de electrooxidación de hidrógeno. La reacción de reducción de oxígeno (RRO) es la reacción determinante del proceso global, debido a que es aproximada- mente cinco órdenes de magnitud más lenta que la reacción de oxidación de hidrógeno $(\mathrm{ROH})$. La reducción lenta del oxígeno conduce a pérdidas en la tensión de las celdas de combustible e impone restricciones en las densidades de potencia. De ahí la necesidad de desarrollar nuevos materiales electrocatalíticos para acelerar esta reacción y obtener así la mayor eficiencia energética posible.

\section{Sobre el vehículo eléctrico}

Un vehículo eléctrico (Faiz, Weaver, \& Walsh, 1996; Reyes-Campaña, Guanuche-Larco, Pulles-Tinoco, \& Aguirre-Stoica, 2021; MaldonadoPáez, Masaquiza-Yanzapanta, Gadvay-aushiña, \& Jima-Matailo, 2020; Trujillo-Sandoval \& García-Torres, 2020) es un vehículo propulsado por uno o más motores eléctricos; puede alimentarse a través de una fuente externa que suministre energía eléctrica, o pueden ser autónomos al tener instalados baterías, paneles solares, o un generador eléctrico que transforme un combustible en electricidad. Los vehículos eléctricos pueden ser, entre otros, vehículos de carretera y ferrocarril, embarcacio- 
nes de superficie y submarinas, aviones eléctricos y naves espaciales eléctricas. Los vehículos eléctricos se pueden clasificar dependiendo del tipo de fuente eléctrica utilizada en su alimentación (Tabla 11).

Tabla 11. Ventajas de vehículos eléctricos a baterías (BEV) y vehículos movidos por celdas de combustible (FCEV)

\begin{tabular}{cc}
\hline \multicolumn{1}{c}{ Ventajas } & Desventajas \\
\hline No producen contaminación atmosférica & Menor autonomía actualmente \\
\hline No producen contaminación acústica & $\begin{array}{c}\text { Lugar de carga (acondicionar garaje, } \\
\text { toma eléctrica, punto de carga externo) }\end{array}$ \\
\hline Ahorro relativo en su mantenimiento & $\begin{array}{c}\text { Precio elevado. Se espera reducciones } \\
\text { a futuro, con los desarrollos }\end{array}$ \\
\hline Mayor espacio para habitabilidad & $\begin{array}{c}\text { Pocos talleres especializados y } \\
\text { limitación en piezas, en la actualidad }\end{array}$ \\
\hline Mayor eficiencia, menor consumo & $\begin{array}{c}\text { Se espera la electricidad para la recarga } \\
\text { desde fuentes no contaminantes }\end{array}$ \\
\hline Larga vida útil &
\end{tabular}

Actualmente son varios los países que ya han comercializado vehículos eléctricos y muchas las investigaciones que se adelantan por su optimización.

\section{Procesos regenerativos con energías no renovables.}

Se desea sustituir a los combustibles fósiles como fuente energética en el planeta, ello motivado a su contribución a la contaminación ambiental, Iluvia ácida y cambio climático. Se está en la búsqueda de fuentes no contaminantes y poco contaminantes, en el primer caso hablamos de la utilización de energías renovables para la obtención de electricidad y del combustible hidrógeno por vía no contaminante. En secciones anteriores se han presentado casos en que por vía electroquímica se culminan procedimientos que conducen a la ausencia o minimización de contaminación y cumplimiento de esta necesidad.

Por vía electroquímica, es también posible el diseño de procesos poco 
contaminantes $y$, en particular, al caso de utilización de compuestos monocarbonados (Figura 8). Con la utilización de estos compuestos es posible obtener altos rendimientos en potencia y muy poca contaminación (relativo a combustibles fósiles). En algunos diseños, es posible además la regeneración del monocarbonado reduciéndose, aún más, la indeseada contaminación.

La alta eficiencia de conversión (> $50 \%$ ) de las celdas de combustible permite un aprovechamiento máximo de la energía química contenida en los combustibles (hidrógeno, metano, metanol, biocombustibles, etc.), asegurando de este modo el uso racional de los recursos.
El metanol presenta las siguientes características en su utilización en la DMFC: -fácil de manipular,-fácil de transportar, -fácil de almacenar, --de relativamente baja toxicidad, -buen almacenador de hidrógeno, -buen almacenador de energía, -alta densidad de energía (orden de $1 \mathrm{kWh} / \mathrm{kg}$ ).

La Figura 8 nos presenta el ciclo redox de monocarbonados y valores altos de eficiencia energética en procesos oxidativos. Es importante la solubilidad del combustible en el medio (solvente apropiado y electrodo poroso con catalizador incorporado).

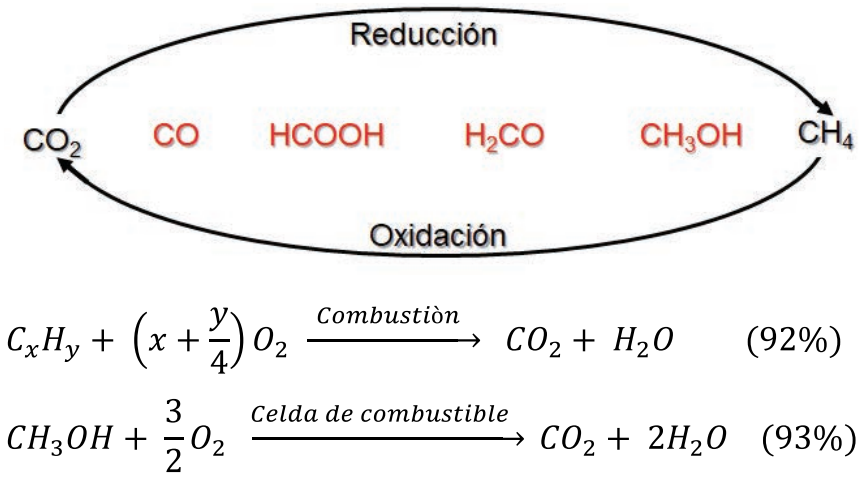


Mostrando como ejemplo la celda de combustible de metanol, DMFC, alimentada con este compuesto, sintetizado en reacción redox $\mathrm{CH}_{4}-\mathrm{CO}_{2}$ se obtiene como producto el dióxido de carbono y energía. El $\mathrm{CO}_{2}$ puede luego ser reconvertido en los reactivos metano y dióxido de carbono, para dar luego reinicio al proceso de obtención de energía.

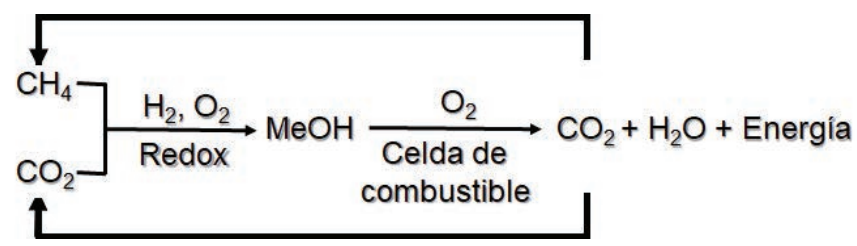

\section{CONCLUSIÓN}

En el campo energético, con fuentes renovables y no renovables, se trabaja en captura, conversión, almacenamiento, suministro y usos de esa energía. Hay importantes adelantos en captura de energías renovables, dispositivos de almacenamiento, sensores, detectores, dispositivos para suministro continuo, plantas energéticas, procesos electrolíticos de interés, además de las celdas solares con materiales poliméricos, éstos tienen aplicaciones como materiales electrónicos, dispositivos optoelectrónicos (celdas electrocrómicas, celdas electroquímicas emisoras de luz, dispositivos fotoconductores), materiales laser, baterías recargables de estado sólido y supercapacitores.
La conversión de energía solar en formas útiles de energía comprende procesos térmicos y fotónicos. En los procesos fotónicos, la energía solar es absorbida en un absorbente y luego convertida en electricidad (celda fotovoltaica) o como energía química (celda fotoelectroquímica o electrolítica). En base a ello, hablamos de sistemas

1) fotoquímicos,

2) fotobiológico,

3) Semiconductor (fotovoltaico, fotoelectroquímico, electroquímico),

4) Hibrido (combinación de los otros). Este trabajo se ha enfocado en referencias a fuentes energéticas y su contribución al cuidado del cambio climático, y en ese 
sentido, se muestran contribuciones de la electroquimienergía, como aportes al control climático sostenido que se desea para el planeta. En resumen, se sugiere (a) el desarrollo de celdas tipo Tandem sensibilizadas, para la captura más eficiente de la radiación solar, la obtención de electricidad, hidrógeno y metanol. (b) reciclaje, repotenciación, (c) el desarrollo de baterías secundarias redox (Ej. BFRV) para suministro energético en sitios aislados, poco accesibles, y también como fuente de respaldo. Uso en estaciones de recarga de vehículos eléctricos. (d) desarrollo de celdas de combustible PMFC y DMFC con sistemas de producción de hidrógeno o metanol incorporado, para suministro energético con diferentes fines. (e) Montaje de plantas para producción de metanol y energía a partir de monocarbonados $\left(\mathrm{CH}_{4} / \mathrm{CO}_{2}\right)$ en procesos cíclicos regenerativos. (f) fotoelectroquímica, producción de hidrógeno en celdas tandem sensibilizadas (g) desarrollos nanoelectroquímicos (partículas, electrodos, catalizadores, componentes, etc.) según sea requerido en los distintos desarrollos.

\section{AGRADECIMIENTOS}

Al laboratorio de Electroquímica de la Ilustre Universidad de Los Andes (Mérida- Venezuela) y, en particular, al grupo de Energía y Petróleo de dicho laboratorio.

\section{LISTA DE REFERENCIAS}

Arenal- Mendoza, R.A., Ángeles-Jiménez, F.J. \& Ávalos-González, F.R.A. (2010). Celdas de Combustible: Diseño, simulación, caracterización y aplicación a la industria. Automotriz. Proyectos de Ingeniería Mecatrónica. Instituto Tecnológico y de estudios superiores de monterrey campus ciudad de México. Ed. Escuela de ingeniería y arquitectura departamento de ingeniería mecatrónica 
Asensio, P. (2020) Hidrógeno y pila de combustible. Energías renovables. p., (1-20) Ed. Fundación de Energía de la Comunidad de Madrid

Balladores, Y., Márquez, J., Martínez, Y., Márquez, O.P., Manfredy, L. \& López-Rivera, S.A. (2014). Double Potentiostatic Deposition and Characterization of Cdln ${ }_{2} \mathrm{Se}_{4}$ Semiconductor, 4(8):439-446.

Barbir, F. (2005). PEM electrolysis for production of Hydrogen from renewable energy sources. Sol. Energy, 78 (5), 661-669. doi:10.1016/j.solener.2004.09.003

Basirun, W.J., Pletcher, D. \& Saraby-Reintjes, A. (1996). Studies of platinum electroplating baths Part IV: Deposits on copper from Q bath. Journal of Applied Electrochemistry, 26(8), 873-880. doi:10.1007/bf00683750

Baxter, J.B., Bian, Z., Chen, G., Danielson, D., Dresselhaus, M.S., Fedorov, A.G., Fishe, T., Jones, C.W., Maginn, E., Kortshagen, U., Manthiram, A., Nozik, A., Sholl, D. $\& W u, Y$. (2009). Nanoscale design to enable the revolution in renewable energy. Energy Environ. Sci., 2, 559-588. Birck and NCN Publications. Paper 405.

Bhandari, R., Trudewind, C.A. \& Zapp, P. (2014) Life Cycle Assessment of Hydrogen Production via Electrolysis Review. Journal of Cleaner Production, 85,151-163.

Bisquert, J. (2005). Sistemas electroquímicos y nanotecnología para el almacenamiento de energía limpia. Univ. Jaume I, 12071 Castelló, España. https://d1 wqtxts1xzle7. cloudfront.net/51289584/2005_almacen_energia-

Bremner, S.P., Levy, M.Y. \& Honsberg, C.B (2008). Analysis of tandem solar cell efficiencies under AM1.5G spectrum using a rapid flux calculation method. Progress in Photovoltaics: Research and Applications, 16(3), 225-233. doi:10.1002/ pip.799

Casadevall, C., Call, A., Codolá, Z., Acuña-Pares, F. \& Lloret-Fillol, J. (2016). Catalizadores para la conversión de energía solar en enlaces químicos. Anales de Química. 112(3), 133-141.

Chen, M., Zhang, Y., Xing, G., Chou, S.L. \& Tang, Y. (2021). Electrochemical energy storage devices working in extreme conditions. Energy \& Environmental Science, 14(6), 3323-3351. doi:10.1039/d1ee00271f 
Datta, D., Mukherjee, P.P. \& Chiu, W.K. (2021) Special Section on Mechanics of Electrochemical Energy Storage and Conversion J. Electrochem. En. Conv. Stor., 18(4) 040301

De Bastiani, M., Mirabelli, A.J., Hou, Y., Gota, F., Aydin, E., Allen, T.G., Troughton, J., Subbiah, A.S., Isikgor, F.H., Liu, J., Xu, L., Chen, B., Van Kerschaver, E., Baran, D., Fraboni, B., Salvador, M.F., Paetzold, U.W., Sargent, E.H. \& De Wolf, S.. Efficient bifacial monolithic perovskite/silicon tandem solar cells via bandgap engineering. Nature Energy, 6(2), 167-175. doi:10.1038/s41560-020-00756

Dincer, I. (2012). Green methods for hydrogen production. International Journal of Hydrogen Energy, 37(2) 1954-1971.

Dincer, I. \& Acar, C. (2015) Review and Evaluation of Hydrogen Production Methods for Better Sustainability. International Journal of Hydrogen Energy, 40(34),1109411111.

Dunn, J. (2007). Hydrogen Futures: Toward a Sustainable Energy System. International Journal of Hydrogen Energy, 27(3) 235-264. https://doi.org/10.1016/S03603199(01)00131-8

El-Shafie, M., Kambara, S. \& Hayakawa, Y. (2019) Hydrogen Production Technologies Overview. Journal of Power and Energy Engineering, 7(1) 107-154. https://doi.org/10.4236/jpee.2019.71007

Esteve-Adell, I., Gil-Agustí, M., Saenz de Zaitegui, L.Z., Quijano-López, A. \& GarcíaPellicer, M. (2020). Aplicaciones del grafeno en sistemas de almacenamiento de energía. Anales de. Química, 116(4) 233-240

Faiz, A., Weaver, C.S. \& Walsh, M.P. (1996). Air Pollution from Motor Vehicles: Standards and Technologies for Controlling Emissions. World Bank Publications. 227. https://doi.org/10.1596/0-8213-3444-1

Fujishima, A. \& Honda, K. (1972). Water Photolysis on $\mathrm{TiO}_{2}$ electrodes. Nature. 238(37-38) https://doi.org/10.1038/238037a0. 
Geisz, J.F., France, R.M., Schulte, K.L., Steiner, M.A., Norman, A.G., Guthrey, H.L., Young, M.R., Tao Song, T. \& Moriarty, T. (2020). Six-junction III-V solar cells with $47.1 \%$ conversion efficiency under 143 Suns concentration. Nat Energy, 5, 326335 https://doi.org/10.1038/s41560-020-0598-5 (2020)

Graetzel, M. (2006). Generation of hydrogen from the solar photolysis of water: Hydrogen Conference. UC Santa Bárbara, USA August 20-25 http://www.icmr.ucsb. edu/programs/archive/documents/Graetzel.pdf

Green, MA. (2002). Third generation photovoltaics: solar cells for 2020 and beyond. Physica E: Low-Dimensional Systems and Nanostructures, 14(1-2), 65-70. doi:10.1016/s1386-9477(02)00361-2

Gregory, A.J., Levason, W. \& Pletche,r D. (1993). Studies of platinum electroplating baths. Journal of Electroanalytical Chemistry, 348(1-2)211-219. doi:10.1016/ 0022-0728(93)80133-3

Guía de la Energía Solar (2006). Dirección General de Industria, Energía y Minas. Obra Social Caja Madrid. Es. www.obrasocialcajamadrid.es_

Ho, P., Thogiti, S., Lee, Y.H. \& Kim, J.H. (2017). Discrete photoelectrodes with dyes having different absorption wavelengths for efficient cobalt-based tandem dyesensitised solar cells. Scientific Reports, 7(1). doi:10.1038/s41598-017-02480-y

Hodes, G. \& Cahen, D. (1986). Electrodeposition of CulnSe 2 and CulnS 2 films. Solar Cells, 16, 245-254. doi:10.1016/0379-6787(86)90088-8 https://analesdequimica.es/index.php/AnalesQuimica/article/view/1334/2212

Kruse, D.A. (2011). Synthesis and characterization of core-shell nanomaterials for solar production of hydrogen fuel. MSc Physics, University of New Mexico, Albuquerque, New Mexico. Physics \& astronomy etds pp. 1-87

Le Penven, R., Levason, W. \& Pletcher, D. (1992). Studies of platinum electroplating baths Part I: The chemistry of a platinum tetrammine bath. J. Appl. Electrochem., 22, 415-420 
Li, C., Song, Z., Chen, C., Xiao, C., Subedi, B., Harvey, S.P., Kamala, N.S., Subedi, K., Chen, L., Liu, D., Li, Y., Kim, Y., Jiang, C., Heben, M.J., Zhao, D., Ellingson, R.J., Podraza, N.J., Al-Jassim, M. \& Yan, Y. (2020). Low-bandgap mixed tin-lead iodide perovskites with reduced methylammonium for simultaneous enhancement of solar cell efficiency and stability. Nature Energy, 5(10), 768-776. doi:10.1038/s41560-020-00692-7

Li, W., Deng, L., Wang, X., Cao, J., Xie, Y., Zhang, Q., Zhang, H., Deng, H. \& Cheng, S. (2021). Close-spaced thermally evaporated 3D Sb2Se3 film for high-rate and high-capacity lithium-ion storage. Nanoscale. 13, 9834-9842 doi:10.1039/ d1 nr01585k

Li, W., Sengupta, N., Dechent, P., Howey, D., Annaswamy, A. \& Sauer, D.U. (2021). Online capacity estimation of lithium-ion batteries with deep long short-term memory networks. Journal of Power Sources, 482, 228863. doi:10.1016/j.jpowsour.2020.22886

Lincot, D., Guillemoles, J.F., Taunier, S., Guimard, D., Sicx-Kurdi, J., Chaumon, A., Roussel, O., Ramdani, O., Hubert, C., Fauvarque, J.P., Bodereau, N., Parissi, L., Panheleux, P., Fanouillere, P., Naghavi, N., Grand, P.P., Benfarah, M., Mogensen, P. \& Kerrec, O. (2004) Chalcopyrite thin film solar cells by electrodeposition. Solar Energy, 77(6), 725-737. doi:10.1016/j.solener.2004.05.024

Lincot, D. (2005). Electrodeposition of semiconductors. Thin Solid Films, 487(1-2), 4048. doi:10.1016/j.tsf.2005.01.032

Lokhande, C.D. (1991). Chemical deposition of metal chalcogenide thin films. Materials Chemistry and Physics, 27(1), 1-43. doi:10.1016/0254-0584(91)90158-q

Maldonado-Páez, F.E., Masaquiza-Yanzapanta, A.G., Gadvay-Ushiña, D.J. \& Jima-Matailo, J.C. (2020). Model of components of an electric vehicle that contribute to an analysis of clean technology in the automotive industry. Pol. Con., 5(8) 689705 doi: $10.23857 /$ pc.v5i8.1618

Manfredy, L., Márquez, O.P., Márquez, J., López-Rivera, S.A., Martínez, Y. \& Balladores, Y. (2014). Electrosynthesis and Characterization of a CulnS 2 Good Absorber Semiconductor for Thin Film Solar Cells. ARPN Journal of Science and Technology, $4(8): 455-463$ 
Mantell, C.L. (2021) Ingeniería Electroquímica, Ed Reverteé, España

Márquez, J., Márquez, O.P., Weinhold, E. \& Márquez, K. (2021). Hidrógeno desde la energía Solar (con Electroquímica). Una revisión. 4(1)11-27.

Márquez, J. \& Márquez, O.P. (2018). Electroquimienergía. Revista de Ingeniería y Tecnología Educativa (RITE), 1(2)9-26.

Márquez, J., Márquez, O.P., Weinhold, E., Márquez, K. \& Balladores, Y. (2021). Vanadio en Celdas Redox con Flujo. Estado Actual: Una Revisión (parte B). Revista Ciencia e Ingeniería, 42(3):351-358.

Márquez, K., Montilla, M., Alarcón, D., Márquez, O.P., Márquez, J. \& Manfredy, L. (2018). La Celda y la Batería Redox de Vanadio. Revista de Ingeniería y Tecnología Educativa (RITE), 1(1):25-40.

Márquez, O.P. \& Márquez, J. (2018). Solid Catalysts for Renewable Energy production. Chapter 11 in Synthesis of electrocatalysts for electrochemistry in energy. IGIglobal, (S González \& F Imbert, Eds.), PA, USA

Moreno, S., Silva, M., Tanides, C., López, A.E. \& Halperin, F. (2017). Uso Racional y Eficiente de la Energía. www.minem.gob.ar/ee., Vázquez Mazzini Ed.

O’M Bockris, J. \& Reddy, A.K.N. (2002). Electrodics. In: Modern Electrochemistry 2A. pp 1035-1400 Springer, Boston, MA. Online ISBN978-0-306-47605-1

Olabi, A.G., Onumaegbu, C., Wilberforce, T., Ramadan, M., Abdelkareem, M.A. \& Al - Alami, A.H. (2020). Critical Review of Energy Storage Systems. Energy, 214 (1) 2021, 118987. doi:10.1016/j.energy.2020.118987

Olabi, A.G., Wilberforce, T. \& Abdelkareem, M.A. (2020). Fuel cell application in the automotive industry and future perspective. Energy, 214 (1) 118955. doi:10.1016/j.energy.2020.118955

Poizot, P., Laruelle, S., Grugeon, S., Dupont, L. \& Tarascon, J.M. (2000). Nano-sized transition-metal oxides as negative-electrode materials for lithium-ion batteries. Nature, 407(6803), 496-99. doi:10.1038/35035045 
Ponce de León, C., Frías-Ferrer, A., González-García, J., Szánto, D.A. \& Walsh, F.C. (2006). Redox flow cells for energy conversion. Journal of Power Sources, 160(1), 716-732. doi:10.1016/j.jpowsour.2006.02.09

Pugach, M., Vyshinsky, V. \& Bischi, A. (2019). Energy efficiency analysis for a kilo-watt class vanadium redox flow battery system. Applied Energy, 253, 113533. doi:10.1016/j.apenergy.2019.11353

Reyes-Campaña, G.G., Guanuche-Larco, D.J., Pulles-Tinoco, S.A. \& Aguirre-Stoica, M.S. (2021). Study of the perception of electric vehicles in the city of Quito. Dom. Cien., 7(5), 937-958 doi: http://dx.doi.org/10.23857/dc.v7i5.2291

Rusu, M., Wiesner, S., Fuertes-Marrón, D., Meeder, A., Doka, S., Bohne, W., Lindner, S., Schedel-Niedrig, Th., Giesen, Ch., Heuken, M. \& Lux-Steiner, M.Ch. (2004). $\mathrm{CuGaSe}_{2}$ thin films prepared by a novel CCSVT technique for photovoltaic application. Thin Solid Films, 451-452, 556-561. doi:10.1016/j.tsf.2003.10.089

Sandoval-Ruiz, C.E. (2020). Arreglos fotovoltaicos inteligentes con modelo LFSR-reconfigurable. Ingeniería, 30(2) 32-61.

Trujillo-Sandoval, DJ. \& García-Torres, E.M. (2020). Respuesta de demanda de energía por introducción de vehículos eléctricos: estado del arte, I+D Tecnológico, 16(1) 5-11. https://doi.org/10.33412/idt.v16.1.2433

Tuller, H.L. (2017). Solar to fuels conversion technologies: a perspective. Materials for Renewable and Sustainable Energy, 6(1)1-16. doi:10.1007/s40243-017-0088-2

Ventosa, E. (2021). Why Nano-electrochemistry is Necessary in Battery Research. Current Opinion in Electrochemistry, 25, 100635- doi:10.1016/j.coelec.2020. 09.002

Villarreal-Archila, S.M., Serrano-Figueroa, C. \& Quiroga-Rojas, D.K. (2021) Evaluation of a mitigation proposal on the final disposal of lead-based batteries and its environmental impact. Ingeniería y competitividad, 23(1), 8720-8732 doi: 10.25100/iyc.23i1.8720 
Wang, Y., Ruiz Diaz, D.F., Chen, K.S., Wang, Z. \& Adroher, X.C. (2020). Materials, technological status, and fundamentals of PEM fuel cells - A review. Materials Today, 32, 178-203 doi:10.1016/j.mattod.2019.06.005

Willkomm, J., Orchard, K.L., Reynal, A., Pastor, E., Durrant, J.R. \& Reisner, E. (2016). Dye-sensitised semiconductors modified with molecular catalysts for light-driven $\mathrm{H}_{2}$ production. Chem. Soc. Rev., 45 (1) 9-23. doi:10.1039/C5CS00733J

Wulfinghoff, D.R. (1999). Fossil Fuels. Energy Efficiency Manual. 1247-1287

Yanagida, M., Onozawa, N., Mitsuhiko, K., Kazuhiro, K. \& Sugihara, S.H. (2010). Optimization of tandem structured dye-sensitized solar cell. K. 94(2) 297-302. doi:10.1016/j.solmat.2009.10.002 